\title{
Design and numerical simulation of a microwave antenna with coaxial slots for preventing secondary formation of gas hydrate
}

\author{
Shujing Wang ${ }^{1}$, Yue Zhu ${ }^{1}$, Volodymyr Bondarenko ${ }^{2}$, Andrii Dreus ${ }^{3}$, Jinqiang Liang ${ }^{4}$, and \\ Baochang Liu ${ }^{1 *}$ \\ ${ }^{1}$ Jilin University, College of Construction Engineering, 938 Ximinzhu St, 130061, Changchun, China \\ ${ }^{2}$ Dnipro University of Technology, Department of Mining Engineering and Education, \\ 19 Yavornytskoho, 49005 Dnipro, Ukraine \\ ${ }^{3}$ Oles Honchar Dnipro National University, Department of Fluid Mechanics and Energy \& Mass \\ Transfer, 72 Haharina Ave., 49089, Dnipro, Ukraine \\ ${ }^{4}$ Key Laboratory of Marine Mineral Resources, Ministry of Land and Resources / Investigation and \\ Research Center for Marine Petroleum and Gas, China Geological Survey, Guangzhou Marine \\ Geological Survey, Guangzhou, 510075, Guangdong, China
}

\begin{abstract}
Gas hydrate is a new clean energy resource with polar molecule. However due to the change of temperature and pressure during extraction process, there will be secondary formation of gas hydrate, which usually occurs in reservoirs or pipelines near the wellhead. It is significance to prevent secondary formation of hydrate because of safety issues or production rate reduction caused by it. Theoretically, microwave heating can accelerate the decomposition of gas hydrate. Therefore, it is possible to use microwave radiation to prevent secondary formation of hydrate. In this paper, a microwave antenna with special shaped coaxialslots was designed. Based on electromagnetics and antenna transmission theories, the key parameters of the coaxial-slot antenna were calculated. The frequency is $2.45 \mathrm{GHz}$, the impedance is $50 \mathrm{ohms}$, and ratio of outer to inner conductor radius is 3.32 . The slots were designed as ' $\mathrm{H}$ '-shape with the width is $2 \mathrm{~mm}$, the radial length is $12 \mathrm{~mm}$, the axial length is $14 \mathrm{~mm}$ and the interval is $35 \mathrm{~mm}$. Teflon was used as filling material and the radome. Then the software HFSS and ANSYS were used to analyze the electromagnetic field and temperature field to further optimize the parameters. It will be proved that the microwave antenna can heat gas hydrate and prevent the secondary formation.
\end{abstract}

\section{Introduction}

Natural gas hydrate is a non-stoichiometric crystalline solid, which is formed by water and small molecular gases (such as $\mathrm{H}_{2}, \mathrm{CH}_{4}, \mathrm{H}_{2} \mathrm{~S}$, etc.) under low temperature and highpressure conditions [1]. At present, depressurization is one of the commonly used methods for producing natural gas hydrate. Studies have shown that in the early (late) stages of gas

*Corresponding author: liubc@jlu.edu.cn 
hydrate decomposition by depressurization, heat transfer and kinetics are the control mechanisms for hydrate decomposition. In the later stage, the heat supply will be insufficient due to the large amount of decomposition and heat absorption of the hydrate in the early stage. Because of the Joule-Thomson effect, there will be secondary formation of gas hydrate in the gas production channels, wellbores, blowout preventers (BOP), and other parts under low temperature and high-pressure conditions. Severe blockage will affect the rate of gas migration or even block gas production channels, causing the risk of reducing gas production rate or even production shutdown [2-7]. In order to eliminate or suppress the secondary hydrate plug in the depressurization process, the supply of heat can restore the gas production efficiency theoretically. The traditional heating method has a slow heating rate and large heat loss. In contrast, the electromagnetic heating method can quickly heat as needed, and it has demonstrated its effectiveness in heavy oil [8-19].

Electromagnetic heating can be divided into high frequency (microwave, radio frequency) heating, medium frequency induction heating, and low frequency resistance heating according to different frequencies. Microwaves are ultra-high frequency electromagnetic waves with frequencies between 300 to $300000 \mathrm{MHz}$. The microwave frequencies between 2450 and $915 \mathrm{MHz}$ are commonly used for heating in the industry. Because microwaves will be absorbed when interacting with some polar substances or molecules to produce thermal effects, microwave heating is widely used in food, industry, agriculture, medical treatment, and the exploitation of unconventional oil and gas resources (oil shale, heavy oil, and oil sands) [20-23].

Natural gas hydrate is a kind of polar molecule. In theory, its molecular motion is disturbed and blocked under the changing electromagnetic field, which will produce an effect similar to friction. And a part of the microwave energy is converted into the energy of the chaotic thermal movement to intensify the movement of the polar molecules, thereby increasing the temperature and solving the problem of insufficient heat supply in the later stage of depressurization [24-27]. Moreover, microwave heating is a kind of body heating, which does not depend on the power system. It means that the temperature can be increased in a short time so that the energy conversion rate is high and the heat loss is small. In this case, the thermodynamic power required for the decomposition of hydrates can be provided, which is beneficial to inhibit the secondary formation of hydrates or promote the decomposition of secondary hydrates, and ultimately improve productivity [28-31].

In the application of microwave heating, the microwave energy generated by the microwave generator is conducted to heat the object through the microwave transmission line. In actual high-power transmission applications, coaxial lines or waveguides are often used as microwave transmission lines, and antenna as a kind of transmission media has the function of radiating microwave energy in a certain direction [22]. At present, the researchers are mainly focused on heating mechanism of heavy oil and gas hydrate by microwave antenna. On the contrary, there are few studies related to the structure design of the antenna for microwave heating of hydrate. For instance, in the case study reported by Kasevich et al. [32], they used antenna to heat a small sample of heavy oil. A microwave antenna with a special protective cover was designed by Matteo et al. [33], which was used to heat the heavy oil. Possibility and capability of gas pipelines used as microwave transmission waveguides was studied and calculated by Wang Yulong [34] and Meng Xiaofeng et al. [35].

The antenna design for heating hydrate is different from that for heating heavy oil because of the different conditions in the process. In this paper, a microwave antenna with coaxial slots suitable for the frequency of $2.45 \mathrm{GHz}$ is designed to prevent the secondary formation of hydrate. The antenna can transmit the high-power microwave energy to the place where the secondary hydrate is easy to form, and radiate microwaves energy in a certain range to heat the secondary hydrate. In addition, it can ensure the normal operation of the antenna while irradiating high microwave power under the conditions of low 
temperature and high pressure. Through the numerical simulation of the HFSS software, the electromagnetic field and temperature field of the secondary gas hydrates was analyzed. The dimension of antenna was optimally designed, which provides a theoretical basis for the removal of secondary hydrates during the exploitation of natural gas hydrates.

\section{Mathematical calculations}

The antenna can radiate effective microwave energy in a specific direction. Monopole antenna is one of the most basic categories and can be used as an omnidirectional antenna. Its basic structure is that the inner conductor of the coaxial cable protrudes from the outer conductor in an appropriate length relative to. Theories and experiments show that the backward heating effect of the monopole antenna is serious, and it will produce a narrow ablation zone with a long tail. In contrast, the heating area formed by the coaxial slot antenna is more ideal. The antenna with coaxial slots is the antenna with some slots on the surface of outer conductor. According to the dimension of the slots, the slots can be divided into radiating slots and non-radiating slots [36-38].

The basic structure of the antenna with coaxial slots designed in this paper is shown in Fig. 1. The antenna is composed of a hollow outer conductor 1 and a solid inner conductor 4. The inner conductor at the top protrudes from the outer conductor with a proper length. The outer conductor is cut to form the slots with $\mathrm{H}$-shaped structure. These radiation slots can cut the microwave line and establish excitation microwave electromagnetic field. The material of the outer conductor 1 can be made by stainless steel in consideration of corrosion resistance, workability and strength. The surface of the outer conductor 1 is uniformly arranged with multiple H-shaped slots in the radial direction to expand the radiation direction range of microwave heating. Copper should be selected as the material of the inner conductor 4 considering its excellent performance in the electronic field. The filler 3 between the inner and outer conductor should be made of low dielectric loss, insulating and impermeable material Teflon. Because of its good pressure resistance, it can also be used as an antenna shell to protect the antenna.

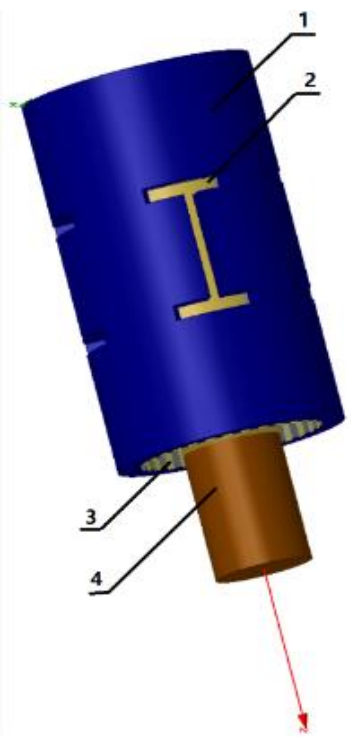

Fig. 1. Structure of the antenna with coaxial slots: 1 - the outer conductor; $2-\mathrm{H}$-shaped slots; 3 filler (Teflon); 4 - the inner conductor. 
Studies have shown that the dielectric properties of hydrates in the microwave frequency range are similar to those of ice and dry sand [39]. The extension length of the inner conductor is related to the effective wavelength in the filler, while the effective wavelength is related to the microwave frequency and relative permittivity. The calculation formula is as follows [39]:

$$
\lambda_{e f f}=\frac{c}{f \sqrt{\varepsilon_{r}}},
$$

where $\lambda_{\text {eff }}$ - the effective wavelength, $\mathrm{m} ; c$ - the speed of light in vacuum, $c=3 \cdot 10^{8} \mathrm{~m} / \mathrm{s}$; $f$ - the frequency of microwave radiation, $\mathrm{Hz} ; \varepsilon_{r}-$ the relative permittivity.

There are transmission electromagnetic waves and cutoff electromagnetic waves due to different frequencies. The frequency determined by the critical state between transmission and cutoff is called cutoff frequency. The wavelength corresponding to this frequency is called cut-off wavelength [39]. When the working wavelength exceeds the cut-off wavelength, only one mode of electromagnetic wave can be transmitted. If it does not exceed this wavelength, multiple modes of waves can be propagated. Since the single-mode transmission is farther than that of multi-mode [34], and the coaxial line is mainly TEM mode. It is necessary to ensure that only the TEM mode is transmitted in the coaxial media, considering the actual long-distance transmission in the actual design.

The calculation of the diameter of the inner and outer conductors of the coaxial slit antenna mainly considers the following two factors [39].

1. The working wavelength must fit the following conditions:

$$
\lambda>1.1 \lambda c(T E M)=1.1 \pi(a+b),
$$

where $\lambda_{c}$ - the working wavelength, $\mathrm{m} ; a$ - the radius of the inner conductor, $\mathrm{mm} ; b$ - the radius of the outer conductor, $\mathrm{mm}$.

2. The antenna should have a large power capacity and a small attenuation coefficient. According to experience, the characteristic impedance can be selected as $50 \Omega$. The ratio of the characteristic impedance to the inner and outer conductor diameters is calculated as follows:

$$
Z_{c}=\frac{60}{\sqrt{\varepsilon_{r}}} \ln \left(\frac{b}{a}\right),
$$

where $Z_{c}$ - the characteristic impedance, $\Omega ; \varepsilon_{r}$ - the relative permittivity of the filler, F/m.

The theoretical value of the slot's length is related to the effective wavelength and relative permittivity. The calculation formula is as follows:

$$
l=\frac{1}{2} \cdot \frac{\lambda_{\text {eff }}}{\left(1+\sqrt{\varepsilon_{r}}\right)},
$$

where $l$ - the length of slots, $\mathrm{mm}$.

The theoretical value of the gap distance is also related to the effective wavelength, and needs to fulfill the requirements of constant amplitude and in-phase feeding. The general calculation formula is as follows:

$$
G=\frac{1}{2} \lambda_{e f f}
$$

where $G$ - the gap distance, $\mathrm{mm}$.

The distance $\left(G_{2}, \mathrm{~mm}\right)$ from the center of the first slot to the microwave input end is usually taken a quarter of the waveguide wavelength: 


$$
G_{2}=\frac{1}{4} \lambda_{e f f}
$$

The antenna needs to be able to work under certain pressure conditions, thus the wall thickness of the outer conductor can be simply calculated by the following formula:

$$
t \geq \frac{K P D}{2 \sigma-K P},
$$

where $t$ - the wall thickness of outer conductor, mm; $K$ - the safety factor, $K=2 ; P$ - the working pressure that needs to be met, $\mathrm{Pa} ; D$ - the diameter of the outer conductor, $\mathrm{m}$; $\sigma-$ the allowable stress of the material selected for the outer conductor, $\mathrm{Pa}$.

The calculation results of main parameters of the antenna are shown in Table 1. The schematic diagram of the size of antenna with coaxial slot is shown in Figs. 2 and 3.

Table 1. The parameters of the antenna with coaxial slots.

\begin{tabular}{|l|c|}
\hline \multicolumn{1}{|c|}{ Parameters } & Value \\
\hline Frequency $f, \mathrm{GHz}$ & 2.45 \\
\hline Effective wavelength $\lambda_{\text {eff }}, \mathrm{mm}$ & 70.7 \\
\hline Characteristic impedance $Z c, \Omega$ & 50 \\
\hline Radius of inner conductor $a, \mathrm{~mm}$ & 4.5 \\
\hline Radius of inner conductor $b, \mathrm{~mm}$ & 15 \\
\hline Wall thickness of outer conductor $t, \mathrm{~mm}$ & 3 \\
\hline Length of slots $l, \mathrm{~mm}$ & 12 (radial direction) / 14 (axial direction) \\
\hline Gap distance $G, \mathrm{~mm}$ & 35 \\
\hline $\begin{array}{l}\text { Distance from the first slot to the } \\
\text { microwave input } G 2, \mathrm{~mm}\end{array}$ & 16 \\
\hline Width of slots $w, \mathrm{~mm}$ & 2 \\
\hline
\end{tabular}
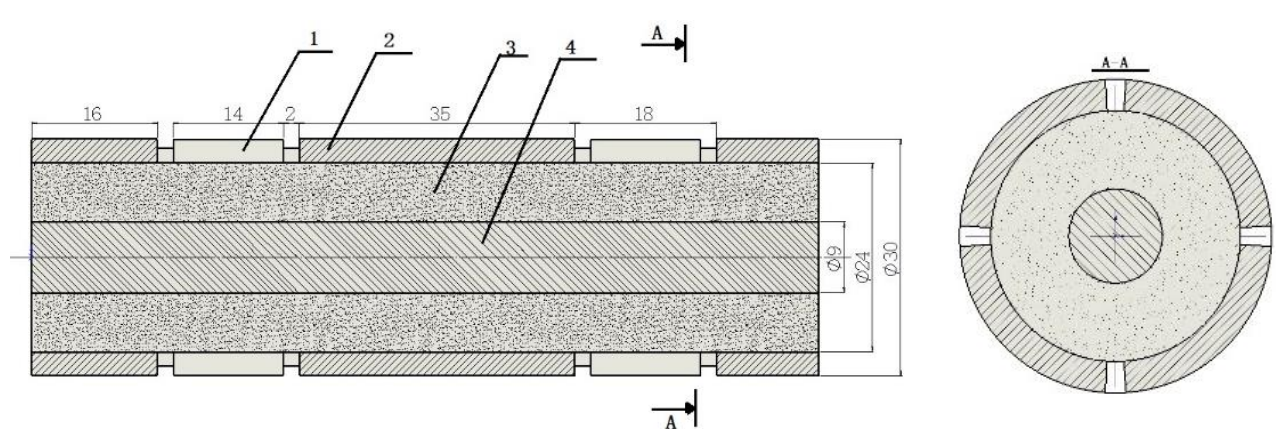

Fig. 2. Schematic diagram of the antenna with coaxial slots: 1 - slot; 2 - the outer conductor; 3 - filler; 4 - the inner conductor.

\section{Results of simulation and discussion}

According to preliminary calculation, using software HFSS and ANSYS to simulate the electromagnetic field and temperature field of the antenna in the process of heating the secondary hydrate. Based on the principle of microwave heating and actual situation of hydrate exploitation [34-41], $2.45 \mathrm{GHz}$ frequency is selected and the remote end of antenna with coaxial slots serves as wave port. 
(a)

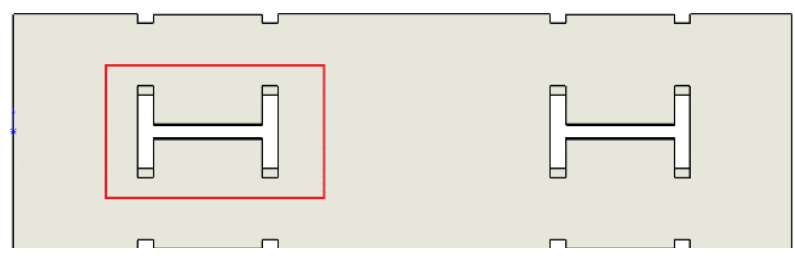

(b)

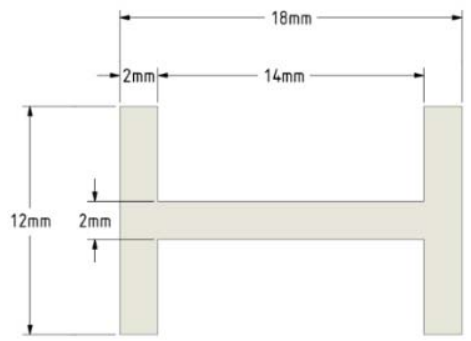

Fig. 3. Schematic diagram of outer surface and slots of antenna: antenna outer surface (a); details (b) of the slot in red square in Figure (a).

The material to be heated is hydrate, which the relative permittivity is 3 and dielectric loss tangent is 0.0006 . The length of antenna is $1000 \mathrm{~mm}$. The radiation area is a cylinder, which the radius is $50 \mathrm{~mm}$ and length is $2000 \mathrm{~mm}$. The model of antenna is showed in Fig. 4.

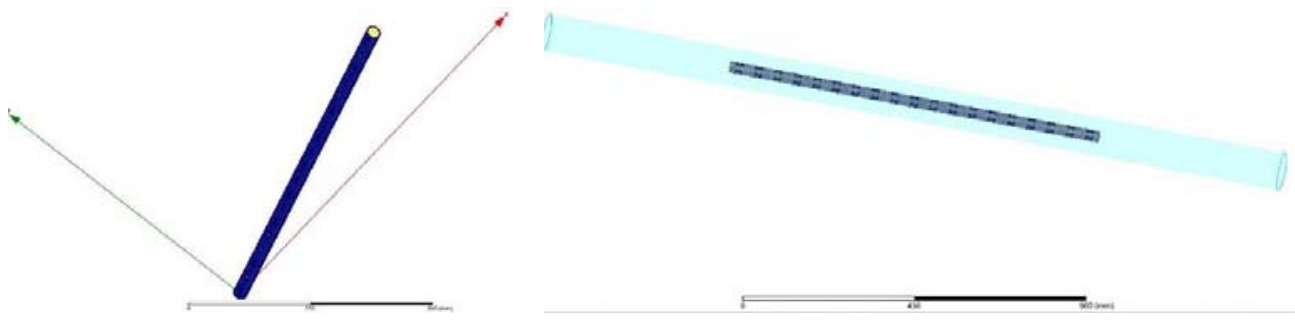

Fig. 4. Design model of antenna and material (hydrate) to be heated.

Tn antenna with coaxial slots mainly relies on the slots opened on the coaxial line and coaxial port to radiate microwave energy to heat hydrate. Under the condition of $2.45 \mathrm{GHz}$, the far-field radiation pattern and 3D polarization plot of the designed antenna are showed in Fig. 5. It can be seen that antenna has a better radiation in all direction, which also proves that the antenna will irritate microwaves through slots to hydrate in all around.

(a)

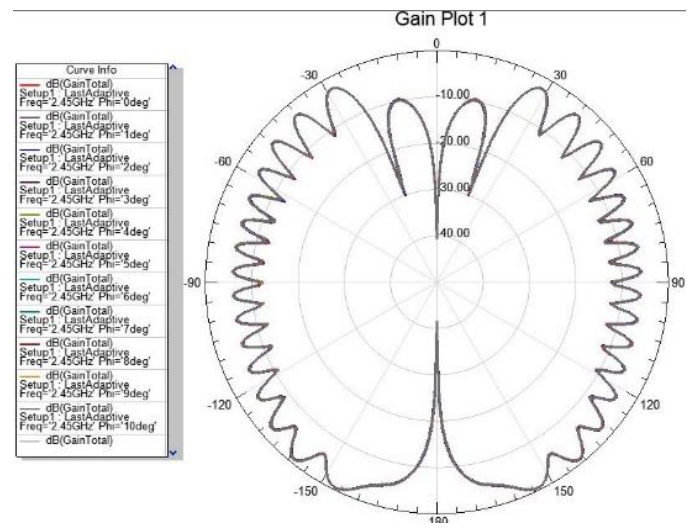

(b)

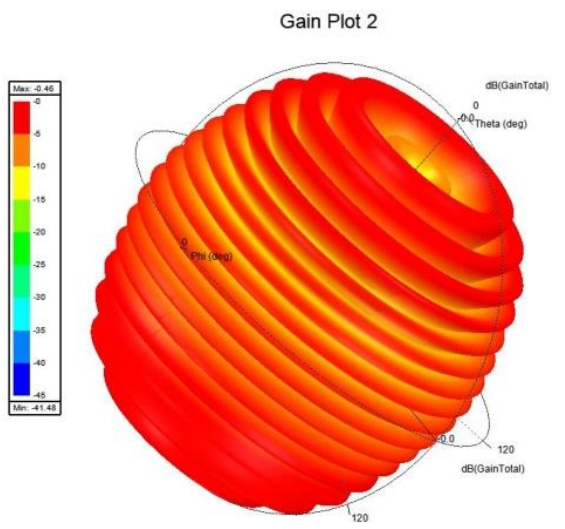

Fig. 5. Simulation field of antenna: far-field radiation pattern of antenna (a); far-field 3D polarization plot (b). 
Considering the thermal properties of hydrates, the temperature field and electric field in the heating process are different. In the heating process, a series of issues such as heat conduction, heat diffusion, and heat dissipation of the cavity need to be considered. Therefore, using software HFSS and ANSYS as a joint simulation. As shown in Fig. 6, solutions of HFSS software are imported into ANSYS to analyze the steady-state thermal and transient thermal of using the antenna heating secondary hydrate.

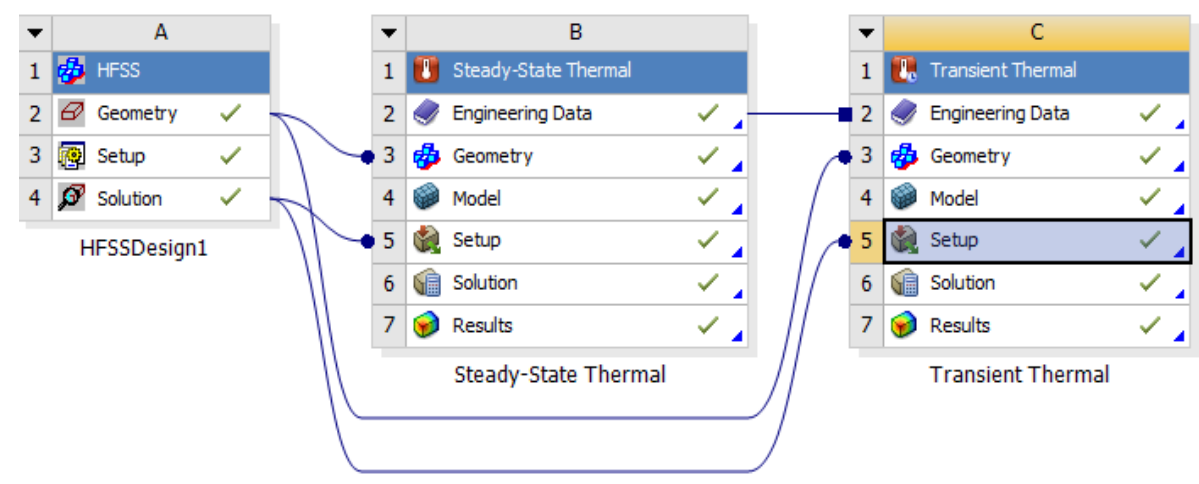

Fig. 6. Joint simulation.

In ANSYS, the energy absorption of each part of the simulation can be seen (Fig. 7). Cylinder 1 is the model of the heated hydrate. The input power is $300 \mathrm{w}$. Since the field and dissipation inside the metal are not calculated in HFSS software, this value is better than the real situation.

Exporting Volume Loss Density With Scaling...
\begin{tabular}{|l|l|l|}
\hline Object & Total Loss & Scaling Factor \\
\hline Outer & OW & 0 \\
\hline jiezhi & $18.9784 \mathrm{~W}$ & 0.728701 \\
\hline Cylinder1 & $2.7371 \mathrm{~W}$ & 0.628306 \\
\hline
\end{tabular}

Fig. 7. Volume loss density of antenna and hydrate.

From the Steady-State thermal simulation (Fig. 8), it shows that the antenna can heat the secondary hydrate to $24^{\circ} \mathrm{C}$. According to the hydrate phase equilibrium theory model, the decomposition condition of hydrate can be satisfied.

(a)

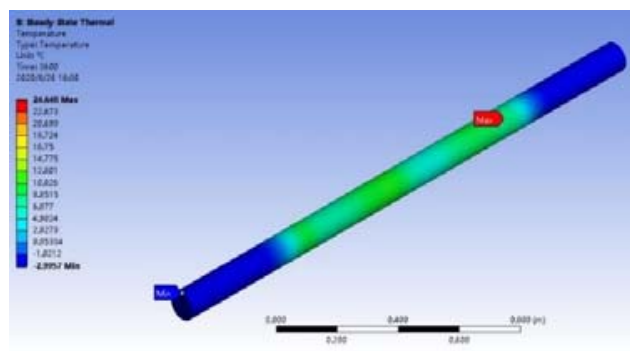

(b)

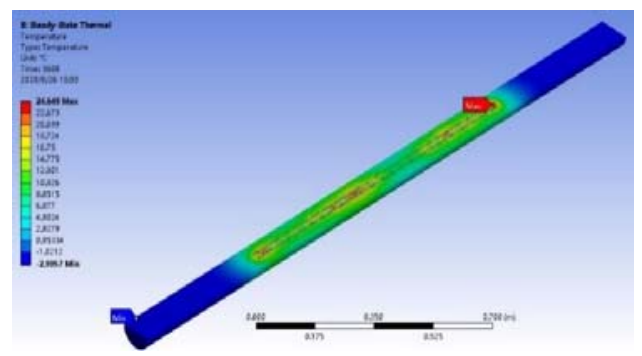

Fig. 8. Steady-state thermal of using the antenna heating secondary hydrate: a panoramic view of the simulation (a); a section view of the simulation (b). 
As shown in Fig. 9, it can be found that the heating rate and temperature uniformity of the antenna to hydrate are effective, which shows that the antenna can achieve the purpose of inhibiting the secondary formation of hydrate.

(a)

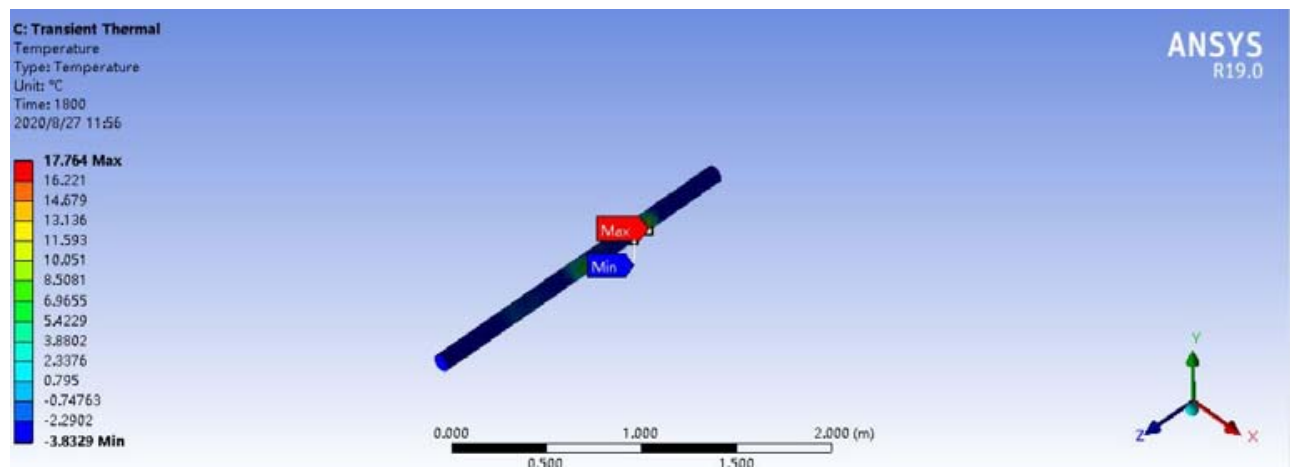

(b)

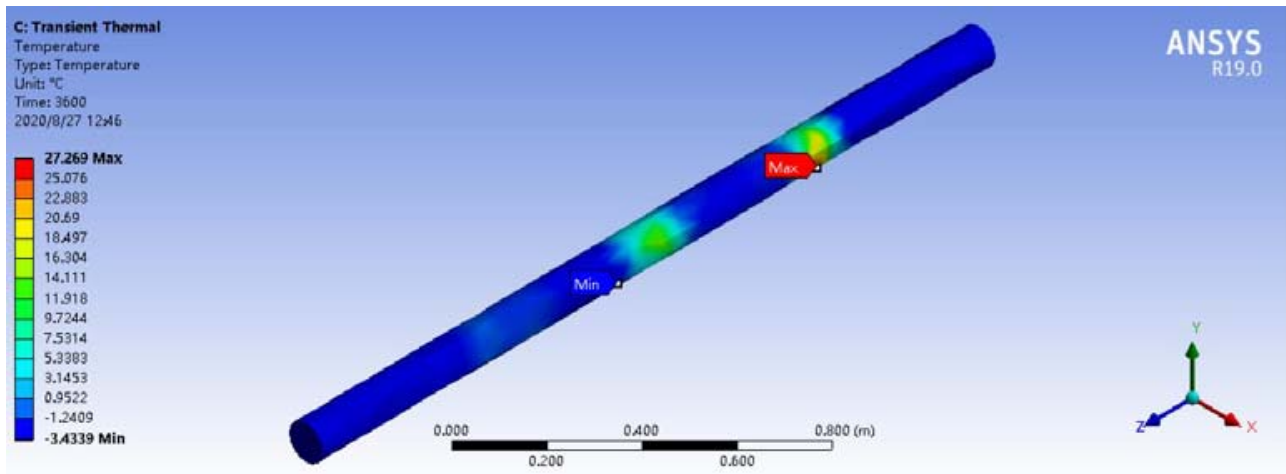

Fig. 9. Trasient thermal of using antenna to heat secondary hydrate: trasient thermal in $1800 \mathrm{~s}$ (a); trasient thermal in $3600 \mathrm{~s}(\mathrm{~b})$.

\section{Conclusions}

The special antenna with coaxial slots which is used to heat secondary hydrates is calculated and designed according to related theories, such as dielectric theory, waveguide theory and slot antenna theory, etc.

The antenna is designed with several ' $\mathrm{H}$ '-shaped slots based on frequency of $2.45 \mathrm{GHz}$, and the diameter of outer conductor is $30 \mathrm{~mm}$, which makes it can be easily lowered into the gas producing channel to prevent the secondary formation of hydrate.

From the simulation results of far-field radiation in HFSS software, the antenna has good omnidirectional radiation. Then combining software HFSS and ANSYS to simulate the heating effect of the antenna on the secondary hydrate. It can be discovered that the secondary hydrate can be heated from -3.8 to $17.8^{\circ} \mathrm{C}$ within $1800 \mathrm{~s}$. While in $3600 \mathrm{~s}$, the hydrate can be heated from -3.4 to $27.3^{\circ} \mathrm{C}$. According to the model of hydrate phase equilibrium, hydrate can be decomposed under this condition. Therefore, based on simulations, it has been demonstrated that the antenna can effectively radiate microwaves to heat hydrates and prevent the secondary formation of hydrates. 
Supported by the Joint research on exploration and development technology of natural gas hydrate, National Key Research and Development Program of China (No. 2018YFE0208200).

\section{References}

1. Haifeng Liang. (2014). Natural gas hydrate decompression production theory and technology. Beijing, China.

2. Xuke Ruan, Xiaosen Li, Mingjun Yang, \& Feng Yu. (2015). Influences of gas hydrate reformation and permeability changes on depressurization recovery. Acta Petrolei Sinica, 36(05), 612-619.

3. Shenglong Wang. (2018). Studies of gas and water migration and particle agglomeration mechanisms in natural gas hydrate exploitation. Dalian University of Technology.

4. Yang, M., Zhao, J., Zheng, J., \& Song, Y. (2019). Hydrate reformation characteristics in natural gas hydrate dissociation process: A review. Applied Energy, (256), 113878. https://doi.org/10.1016/j.apenergy.2019.113878

5. Pivnyak, G., Bondarenko, V., Kovalevs'ka, I., \& Illiashov, M. (2012). Geomechanical processes during underground mining. London, United Kingdom: CRC Press, Taylor \& Francis Group.

6. Bondarenko, V., Kovalevs'ka, I., \& Ganushevych, K. (2014). Progressive technologies of coal, coalbed methane, and ores mining. London, United Kingdom: CRC Press, Taylor \& Francis Group. https://doi.org/10.1201/b17547

7. Pivnyak, G., Bondarenko, V., \& Kovalevska, I. (2015). New developments in mining engineering 2015. London, United Kingdom: CRC Press, Taylor \& Francis Group. https://doi.org/10.1201/b19901

8. Tao Xu. (2009). A mathematical model study on heavy oil well stimulated by nonwireline electromagnetic heating. Dalian University of Technology.

9. Chhetri, A.B., \& Islam, M.R. (2008). A critical review of electromagnetic heating for enhanced oil recovery. Petroleum Science and Technology, 26(14), 1619-1631. https://doi.org/10.1080/10916460701287607

10. Rehman, M.M., \& Meribout, M. (2012). Conventional versus electrical enhanced oil recovery: A review. Journal of Petroleum Exploration and Production Technology, 2(4), 157-167. https://doi.org/10.1007/s13202-012-0034-x

11. Mukhametshina, A., \& Martynova, E. (2013). Electromagnetic heating of heavy oil and bitumen: a review of experimental studies and field applications. Journal of Petroleum Engineering, (2013), 1-7. https://doi.org/10.1155/2013/476519

12. Tran, T.S. (2009). Electromagnetic assisted carbonated water flooding in heavy oil recovery. Delft University of Technology.

13. Chhetri, A.B., \& Islam, M.R. (2008). A critical review of electromagnetic heating for enhanced oil recovery. Petroleum Science and Technology, 26(14), 1619-1631. https://doi.org/10.1080/10916460701287607

14. Bondarenko, V.I., \& Sai, K.S. (2018). Process pattern of heterogeneous gas hydrate deposits dissociation. Naukovyi Visnyk Natsionalnoho Hirnychoho Universytetu, (2), 21-28. https://doi.org/10.29202/nvngu/2018-2/4

15. Ganushevych, K., \& Sai, K. (2020). Technological aspects of the development of gas hydrate deposits with the use of carbon dioxide injection. E3S Web of Conferences, (201), 01023. https://doi.org/10.1051/e3sconf/202020101023

16. Yi Zhao, Feiyue Zhu, \& Zhaobin Diao. (2017). Research on inhibiting hydrate formation in the process of oil and gas transportation. China Petrochem, 17(08), 86-87.

17. Bondarenko, V., Svietkina, O., \& Sai, K. (2018). Effect of mechanoactivated chemical additives on the process of gas hydrate formation. Eastern-European Journal of Enterprise Technologies, 6(91), 17-26. https://doi.org/10.15587/1729-4061.2018.123885 
18. Maksymova, E., Ovchynnikov, M., Lysenko, R., \& Kostrytska, S. (2018). Physical and chemical methods of methane utilization in Ukrainian coal mines. Solid State Phenomena, (277), 147-156. https://doi.org/10.4028/www.scientific.net/SSP.277.147

19. Bondarenko, V., Svietkina, O., Lysenko, R., \& Liu, B. (2020). Methane gas hydrates influence on sudden coal and gas outbursts during underground mining of coal deposits. E3S Web of Conferences, (201), 01002. https://doi.org/10.1051/e3sconf/202020101002

20. Zhaogia Zhang, \& Ruoqing Zhong. (1988). Microwave heating technology. Beijing, China: Publishing House of Electronics Industry.

21. Jinhun Peng, \& Xianwan Yang. (1997). New applications of microwave energy technology. Kun Ming, China: Yunnan Science and Technology Press.

22. Zhaotang Zhang. (2018). Magnetron and microwave heating technology. Cheng Du, China: Press of University of Electronic Science and Technology.

23. Bondarenko, V., Kovalevska, I., Astafiev, D., \& Malova, O. (2018). Examination of phase transition of mine methane to gas hydrates and their sudden failure - Percy Bridgman's effect. Solid State Phenomena, (277), 137-146. https://doi.org/10.4028/www.scientific.net/SSP.277.137

24. Zhaozhong Yang, Jingyi Zhu, \& Xiaogang Li. (2016). Progress in researches on microwave heating in unconventional oil resources. Chemical Industry and Engineering Progress, 35(11), 3478-3483.

25. Qiwen Deng. (2018). Research progress on viscous oil viscosity reduction mining technology. Chemical Engineering Design Communications, 44(9), 124.

26. Meihui Zhang. (2014). Technical research on improving heavy oil production. China Petroleum and Chemical Standard and Quality, 34(10), 37.

27. Rujie Liu. (2019). Exploration and practice of improving uniform producing technology of horizontal sections with ultra heavy oil. Sino-Global Energy, (24), 52-58.

28. Bera, A., \& Babadagli, T. (2015). Status of electromagnetic heating for enhanced heavy oil/bitumen recovery and future prospects: A review. Applied Energy, (151), 206-226. https://doi.org/10.1016/j.apenergy.2015.04.031

29. Qunying Mou, \& Xianjun Li. (2004). Application and research progress of microwave heating technology. Physics, 33(6), 438- 442.

30. Yonglin Zhang. (1999). Component function and structure of microwave heating system. Journal of Wuhan Polylechnic University, (2), 40- 43.

31. Zefu Bao, \& Jiangping Wang. (2006). Application of microwave heating technique in natural gas transportation. China Petroleum Machinery, 34(9), 95-96.

32. Kasevich, R.S., Price, S.L., Faust, D.L., \& Fontaine, M.F. (1994). Pilot testing of a radio frequency heating system for enhanced oil recovery from diatomaceous earth. SPE Annual Technical Conference and Exhibition. https://doi.org/10.2118/28619-ms

33. Bientinesi, M., Petarca, L., Cerutti, A., Bandinelli, M., De Simoni, M., Manotti, M., \& Maddinelli, G. (2013). A radiofrequency/microwave heating method for thermal heavy oil recovery based on a novel tight-shell conceptual design. Journal of Petroleum Science and Engineering, (107), 18-30. https://doi.org/10.1016/j.petrol.2013.02.014

34. Yulong Wang. (2013). Feasibility study of natural gas hydrate in gas pipeline unplugging by using microwave. Xi'an Shiyou University.

35. Xiaofeng Meng, Yijian Chen, \& Jing Zhou. (2010). Analysing microwave propagation properties in drilling stem. Journal of Beijing Normal University (Natural Science), 46(02), 151-155.

36. Zheng Song, Jianhua Zhang, \& Wei Tang. (2017). Electromagnetic field, microwave technology and antenna. Press of Xidian University.

37. Chuangming Dong, Jiangang Liang, \& Zhiqin Ju. (2009). Electromagnetic, microwave technology and antenna. Northwestern Polytechnical University Press.

38. Yingxu Jiang. (2018). The research on key techniques of microwave conformal ablation and dose control of tumors. Nanjing University of Aeronautics and Astronautics the Graduate School.

39. Song He, Deqing Liang, Dongliang Li, \& Longlong Ma. (2011). Removal of hydrate plugs by 2.45 
GHz microwave radiation. Journal of Chemical Industry And Engineering (China), 62(01), 206-213.

40. Nevels, R.D., Arndt, G.D., Raffoul, G.W., Carl, J.R., \& Pacifico, A. (1998). Microwave catheter design. IEEE Transactions on Biomedical Engineering, 45(7), 885-890. https://doi.org/10.1109/10.686796

41. Shuxia Li, Shangping Guo, Yueming Chen, Ningtao Zhang, \& Didi Wu. (2020). Advances and recommendations for multi-field characteristics and coupling seepage in natural gas hydrate development. Chinese Journal of Theoretical and Applied Mechanics, 52(03), 828-842. 